\title{
RhoA regulates invasion of glioma cells via the c-Jun NH2-terminal kinase pathway under hypoxia
}

\author{
JIAO JIAN TONG, ZHANG YAN, REN JIAN, HUANG TAO, OUYANG TAO HUI and CHEN JIAN \\ Department of Neurosurgery, Tongji Hospital, Tongji Medical College, \\ Huazhong University of Science and Technology, Wuhan, Hubei 430030, P.R. China
}

Received February 29, 2012; Accepted June 12, 2012

DOI: $10.3892 / \mathrm{ol} .2012 .777$

\begin{abstract}
The purpose of this study was to investigate the mechanism of glioma cell invasion in hypoxic conditions. We demonstrated that hypoxia increased cell invasion, matrix metalloproteinase-2 (MMP2) activity and time-dependent expression of hypoxia inducible factor- $1 \alpha(\mathrm{HIF}-1 \alpha)$ in human glioma cells. These data suggest that MMP2 may play a significant role in tumor invasion in hypoxic conditions. We investigated the mechanisms involved in the increased MMP2 activity and cell invasion in hypoxic conditions. Increased expression of phospho-Jun NH2-terminal kinase (p-JNK) and phospho-c-Jun (p-c-Jun) in glioma cells induced by hypoxia was detected. Furthermore, this effect may be reduced by inhibiting the JNK signaling pathway. We found that inhibition of RhoA geranylgeranylation by geranylgeranyltransferase inhibitor-2147 (GGTI-2147) or knockdown of RhoA by siRNA against RhoA reduced the expression of p-JNK and p-c-Jun, and decreased MMP2 activity and glioma cell invasion in hypoxic conditions. These data suggest a link among RhoA, JNK, c-Jun and MMP2 activity that is functionally involved in the increased glioma cell invasion induced by hypoxia.
\end{abstract}

\section{Introduction}

Glioblastoma (GBM) is the most common and malignant type of tumor of the central nervous system (1-3), and is characterized by its rapid proliferation and widespread invasion from tumor sites to surrounding normal brain tissues. Despite recent advances in treatments and understanding of the molecular mechanism, the median survival time for patients with GBM is only 10-12 months (4-5). In addition, the high growth rate of tumor cells contributes to a pathophysiological consequence:

Correspondence to: Professor Chen Jian, Department of Neurosurgery, Tongji Hospital, Tongji Medical College, Huazhong University of Science and Technology, Wuhan, Hubei 430030, P.R. China

E-mail: tjcj39280@yahoo.com.cn

Key words: glioma, cell invasion, hypoxia, U251 cell line, RhoA-JNK signaling pathway, matrix metalloproteinase-2 hypoxia, which is a source of stress for cancer cells. Cancer cells undergo genetic and adaptive changes in a hypoxic environment that contribute to aggressive tumor behavior (6). The aggressive tumor behavior is dependent on the capacity of cancer cells to invade and migrate, and is closely linked to the activity of matrix metalloproteinases (MMPs) which regulate cell invasion, migration and extracellular matrix degradation (7-9). The increase in expression and activity of matrix metalloproteinases-2 (MMP2) and -9 (MMP9) has been correlated with an increased grade of glioma (10-12).

Inhibitors of geranylgeranyltransferase I (13) block posttranslational geranylgeranylation of the small $\mathrm{G}$ protein RhoA and inhibit the ability of RhoA to translocate from the cytosol to the plasma membrane $(14,15)$. Interacted with the plasma membrane, RhoA modulates downstream signaling pathways to regulate the cell cycle and survival $(16,17)$. In addition, RhoA plays an essential role in cancer cell migration and invasion (18-20). However, it is not fully understood whether RhoA is capable of regulating MMPs and cell migration and invasion in a hypoxic condition. In this study, we demonstrate that inactivation or reduced expression of RhoA decreases cell migration and invasion induced by hypoxia in human glioma cells through the inhibition of the c-Jun NH2-terminal kinase (JNK) signaling pathway and MMP2 activity. Our results suggest that RhoA and JNK play an essential role in human glioma cell migration and invasion induced by hypoxia.

\section{Materials and methods}

Antibodies and reagents. We used antibodies specific to hypoxia inducible factor- $1 \alpha$ (HIF-1 $\alpha)$, phospho-JNK (Thr183/185), JNK, phospho-c-Jun (Ser63/73), c-Jun and RhoA (Santa Cruz Biotechnology, Inc., Santa Cruz, CA, USA). Anti- $\beta$-actin was purchased from Abmart (Shanghai, China). Antibodies against $\mathrm{Na} / \mathrm{K}$ ATPase and geranylgeranyltransferase inhibitor-2147 (GGTI-2147) were purchased from Sigma (St. Louis, MO, USA). The membrane protein extraction kit was purchased from BioVision (Mountain View, CA, USA).

Cell culture. Human glioma U251 cells were purchased from Shanghai Institutes for Biological Sciences (SIBS) of Chinese Academy of Sciences (CAS). Cells were maintained in Dulbecco's modified Eagle's medium (DMEM)/nutrient mixture F12 (Gibco) supplemented with 10\% FBS (Hyclone, 
Logan, UT, USA) and were incubated at $37^{\circ} \mathrm{C}$ in a humidified incubator with $5 \% \mathrm{CO}_{2}$ and $95 \%$ air.

Hypoxic and normoxic conditions. Hypoxic conditions were created in an airtight chamber deoxygenated with the constant infusion of a hypoxic gas mixture $\left(37^{\circ} \mathrm{C}, 5 \% \mathrm{CO}_{2}, 1 \% \mathrm{O}_{2}\right.$, $94 \% \mathrm{~N}_{2}$ ). The $\mathrm{O}_{2}$ content was monitored with an $\mathrm{O}_{2}$ analyzer. Similarly, normoxic conditions were maintained in a standard incubator $\left(37^{\circ} \mathrm{C}, 5 \% \mathrm{CO}_{2}, 20 \% \mathrm{O}_{2}\right.$, balanced $\left.\mathrm{N}_{2}\right)$.

Knockdown of RhoA protein. RhoA protein was knocked down using small interfering RNA (siRNA) against RhoA mRNA. The siRNA was obtained from Santa Cruz Biotechnology (sc-29471). A negative control siRNA (sc-44230, Santa Cruz) was used as a control. The sequences of these siRNAs were not disclosed by the companies. U251 cells were transfected with $1 \mu \mathrm{g}$ siRNA against RhoA mRNA or a control siRNA using Lipofectamine $^{\mathrm{TM}} 2000$ (Invitrogen) in Opti-MEM serum-free medium (Invitrogen) according to the manufacturer's instructions. U251 cells were exposed to hypoxia or normoxia. Then RhoA activity and protein levels of RhoA were analyzed.

Cell invasion assays. Cell invasion assays were performed using a Transwell system that incorporated a polycarbonate filter membrane with a diameter of $6.5 \mathrm{~mm}$ and pore size of $8 \mu \mathrm{m}$ (Corning, NY, USA). To assess invasion, filters were coated with $10 \mu \mathrm{g}$ BD Matrigel ${ }^{\mathrm{TM}}$ (BD Biosciences, Franklin Lakes, NJ, USA). Following the manufacturer's instructions, cells $\left(1 \times 10^{5}\right.$ cells $)$ in $100 \mu \mathrm{l}$ serum-free medium were added to the upper chamber and the lower chamber was filled with DMEM containing $10 \% \mathrm{FBS}$ as a chemoattractant. After $24 \mathrm{~h}$ incubation at $37^{\circ} \mathrm{C}$, the non-invasive cells were removed from the upper chamber, and filters were fixed with $100 \%$ methanol and stained with a $0.1 \%$ crystal violet solution for $10 \mathrm{~min}$. The number of invading cells was manually counted as the sum of 5 randomly selected fields at x 20 magnification using an Olympus IX70 fluorescence microscope (Center Valley, PA, USA).

Western blotting. Cells were lysed in western blotting lysis buffer [50 mM Tris- $\mathrm{HCl}(\mathrm{pH} 8), 150 \mathrm{mM} \mathrm{NaCl}, 1 \% \mathrm{NP}-40$, 2 mM EDTA (pH 8), $10 \mathrm{mM} \mathrm{NaF}, 1 \mathrm{mM} \mathrm{Na} \mathrm{VO}_{4}, 1 \mathrm{mM}$ PMSF, aprotinin and leupeptin each at $10 \mathrm{pg} / \mathrm{ml}, 0.5 \%$ deoxycholic acid and $0.1 \% \mathrm{SDS}$ ] for $30 \mathrm{~min}$ on ice. The lysates were clarified by centrifugation and protein concentrations were measured. Proteins were separated in SDS-polyacrylamide gel and transferred to nitrocellulose. Nitrocellulose was blocked in $3 \%$ goat serum for $1 \mathrm{~h}$ at room temperature and then incubated with primary antibodies followed by incubation with horseradish peroxidase-conjugated secondary antibodies. Both antibodies were diluted in washing buffer containing $1 \%$ BSA. The blots were developed by the enhanced chemiluminescence technique (ECL kit, Amersham Biosciences, Sunnyvale, CA, USA). Representative results from at least 3 independent experiments are shown. Densitometry was performed using Image J software.

Gelatin zymography. Gelatin (Biotech, Shanghai, China) was dissolved in distilled water at a concentration of $1 \%$, autoclaved, cooled and stored at $4^{\circ} \mathrm{C}$. The transfected cells were incubated in serum-free DMEM for $24 \mathrm{~h}$. The conditioned medium was collected and centrifuged for $5 \mathrm{~min}$ at $10,000 \mathrm{x} \mathrm{g}$ to discard unsoluble materials. Total protein content was determined by a colorimetric assay using BCA protein dye. $10 \%$ SDS-polyacrylamide gel containing $0.1 \%$ gelatin was polymerized and the medium was separated in the gel without prior boiling. The gel was washed in $2.5 \%$ Triton X-100 in water for $1 \mathrm{~h}$ to remove residual SDS and then incubated in developing buffer [50 mM Tris- $\mathrm{HCl}(\mathrm{pH} 7.5), 5 \mathrm{mM} \mathrm{CaCl}_{2}$, $150 \mathrm{mM} \mathrm{NaCl}$ and $0.02 \%$ sodium azide] for $24 \mathrm{~h}$ at $37^{\circ} \mathrm{C}$ to promote the activity of proteinases. The gel was stained with $0.5 \%$ Coomassie Brilliant Blue for $1 \mathrm{~h}$ and then destained with $30 \%$ methanol and $10 \%$ acetic acid. Proteolysis was detected as a white zone on a dark field. The intensity of the bands was quantified using Image J (version 1.34).

Statistical analysis. The figures show data obtained in at least three independent experiments as indicated. Quantitative data were expressed as the means \pm SE. Analysis of variance and Student's t-test were used to analyze the difference between the means of test samples and controls, and $\mathrm{P}<0.05$ was considered to indicate a statistically significant result $\left({ }^{*} \mathrm{P}<0.05,{ }^{* *} \mathrm{P}<0.01\right)$.

\section{Results}

Hypoxia increases glioma cell invasion and MMP2 activity. We firstly created hypoxic conditions and examined the expression of HIF-1 $\alpha$ in U251 cells in hypoxic conditions. Our data revealed that hypoxia induced the expression of HIF-1 $\alpha$ in hypoxic conditions (Fig. 1A). To examine the effect of hypoxia on glioma cell invasion, Transwell assay was performed using U251 cells. U251 cells were incubated in the Transwell chamber under normoxic and hypoxic conditions for $24 \mathrm{~h}$, and the cells were stained with Coomassie Brilliant Blue. The cells that migrated to the lower chamber were counted from four randomly selected areas per well. Our data demonstrated that hypoxia increased the invasion of U251 cells (Fig. 1B). We examined whether MMP expression contributed to the increased invasion under hypoxia. The enzymatic activity of MMP2 was measured at $24 \mathrm{~h}$ following hypoxia by gelatin zymography. Our data revealed that hypoxia enhances U251 cell invasion by inducing MMP2 expression (Fig. 1C).

Inhibition of JNK decreases the ratio of $p$-c-jun/c-jun and p-JNK/JNK, MMP2 activity and glioma cell invasion under hypoxic conditions. To elucidate the molecular mechanisms of the effect of hypoxia on the invasion of U251 cells, we measured the ratio of p-jun/jun and p-JNK/JNK at 0,12 and $24 \mathrm{~h}$ in hypoxic conditions. Hypoxia was found to increase the ratio of p-c-jun/c-jun and p-JNK/JNK (Fig. 2A). We thus evaluated the effect of JNK signaling pathway inhibition on the hypoxia-induced increase of U251 cell invasion. We found that the addition of SP600125 decreased the ratio of p-c-jun/c-jun and p-JNK/JNK in U251 cells in hypoxic conditions (Fig. 2B). To fully confirm the involvement of the JNK signaling pathway in the increase of cell invasion induced by hypoxia, we treated U251 cells with SP600125 for $24 \mathrm{~h}$ under hypoxic conditions and collected cell culture medium samples. We examined MMP2 activity using gelatin zymography assays. Our data revealed that the JNK inhibitor decreased MMP2 activity induced by 
A

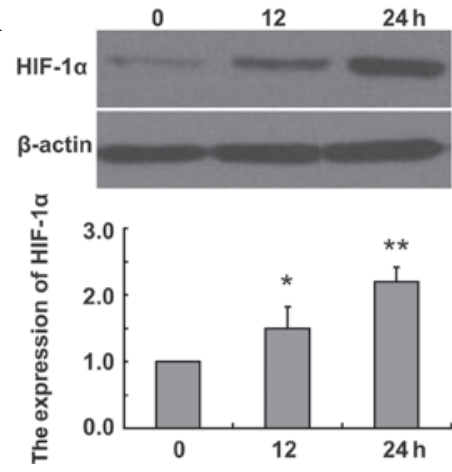

B
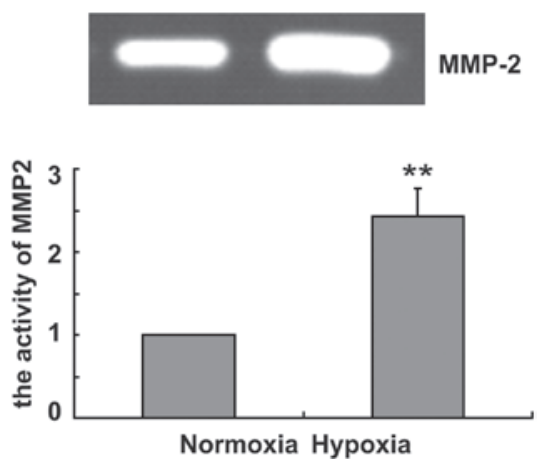

C
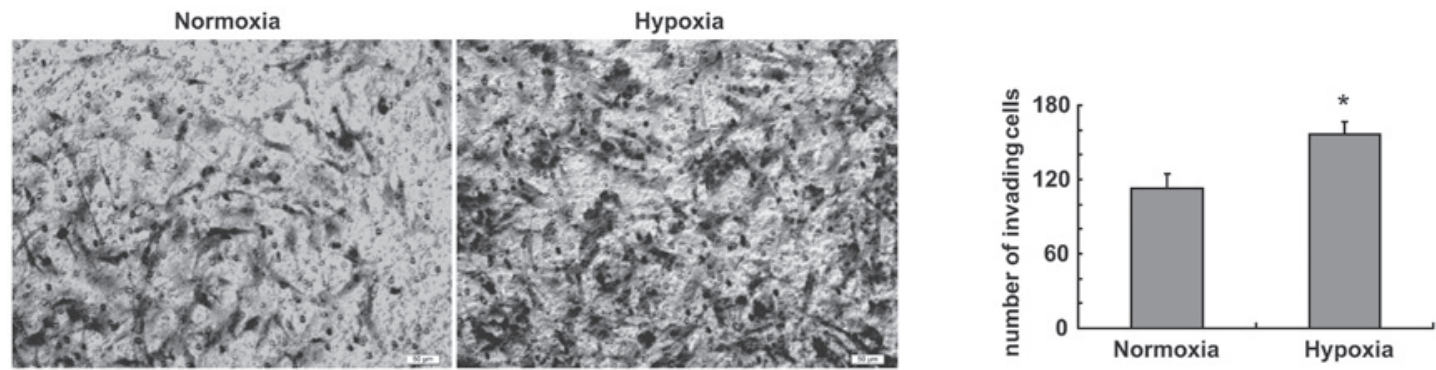

Figure 1. Hypoxia increases glioma cell invasion and MMP2 activity. (A) Western blot analysis shows the time-dependent effect of hypoxia on levels of HIF-1 $\alpha$ in U251 cells. The bar graph shows relative expression of HIF-1 $\alpha$ in hypoxia-treated cells versus those in control cells ( $\mathrm{P}<0.05$, $\left.{ }^{* *} \mathrm{P}<0.01\right)$. (B) $\mathrm{U} 251$ cells were incubated under normoxic or hypoxic conditions for $24 \mathrm{~h}$ and cell culture medium samples were collected. Gelatin zymography assays show the effect of hypoxia on enzymatic activity of MMP2. The bar graph shows the relative integrated densities of the bands in hypoxia-treated cells versus those in control cells $\left({ }^{* *} \mathrm{P}<0.01\right)$. (C) U251 cells were incubated in a Transwell chamber under normoxic or hypoxic conditions for $24 \mathrm{~h}$, and the cells were stained with Coomassie Brilliant Blue. The bar graph shows mean number of migrated cells $\left({ }^{*} \mathrm{P}<0.05\right)$.

hypoxia (Fig. 2C). To further demonstrate the role of the JNK signaling pathway in cell invasion, we performed Matrigel invasion tests with U251 cells treated with SP600125. We found that the inhibition of the JNK signaling pathway decreased the invasion of U251 cells in hypoxic conditions (Fig. 2D).

Inactivition or knockdown of RhoA inhibits the JNK signaling pathway and decreases MMP2 activity and glioma cell invasion in hypoxic conditions. Finally, to evaluate the link between RhoA and the JNK signaling pathway, we also examined the expression of RhoA and active RhoA in U251 cells in hypoxic conditions. We found that hypoxia had the same time-dependent effect on the expression of active RhoA and RhoA (Fig. 3A). To investigate whether the production of p-jun and $\mathrm{p}-\mathrm{JNK}$ could be blocked by functional inactivation of RhoA, U251 cells were incubated under hypoxia for $24 \mathrm{~h}$ after U251 cells were treated with GGTI-2147 or transfected RhoA siRNA. Then western blot analysis was performed. Our data revealed that the expression of active RhoA decreased and the ratio of p-jun/jun and p-JNK/JNK also decreased (Fig. 3B). To investigate whether the activity of MMP2 was affected by GGTI-2147 or RhoA knockdown, the enzymatic activity of MMP2 was measured at $24 \mathrm{~h}$ following hypoxia by gelatin zymography after U251 cells were treated with GGTI-2147 or transfected RhoA siRNA. Our data showed that the activity of MMP2 was reduced in GGTI-2147-treated cells or RhoA siRNA-transfected cells under hypoxia compared with control cells under hypoxia (Fig. 3C). To determine whether active RhoA was involved in glioma cell invasion, we compared the invasive capacity of GGTI-treated or RhoA knockdown cells and control cells. Directed invasion of U251 cells was significantly reduced by the inhibition of active RhoA or the loss of RhoA under hypoxia, respectively, when compared with controls in hypoxic conditions (Fig. 3D).

\section{Discussion}

In this study, we demonstrated that knockdown or inactivation of RhoA decreased the invasion of glioma cells and the activity of MMP2 under hypoxic conditions, and we identified a molecular mechanism involving JNK-c-jun-MMP2 activity in effect in hypoxic conditions. These data point to a potential antitumoral effect mediated by the inhibition of RhoA and JNK-c-jun-MMP2 activity in glioma cells under hypoxic conditions.

Hypoxia is an important aspect of the glioma microoenvironment, and has been correlated with poor prognosis, increased angiogenesis, tumor growth and resistance to radiotherapy and chemotherapy (21). The role that hypoxia plays in glioma cell migration and invasion is well established (22). We also demonstrated that hypoxia increases cell invasion in the human glioma cell line. This suggests a direct effect of hypoxia on invasion of tumor cells. We hypothesized that the increase in glioma cell invasion induced by hypoxia in our experiment may result from increased activity of MMPs. This is supported by our finding that hypoxia increases the activity of MMP2. Indeed, abnormal expression of MMPs is thought to play a critical role in tumor cell invasion in several cancers (23-25) including glioma (26).

Having established that glioma cell invasion and activity of MMP2 may be induced by hypoxia, we investigated the 

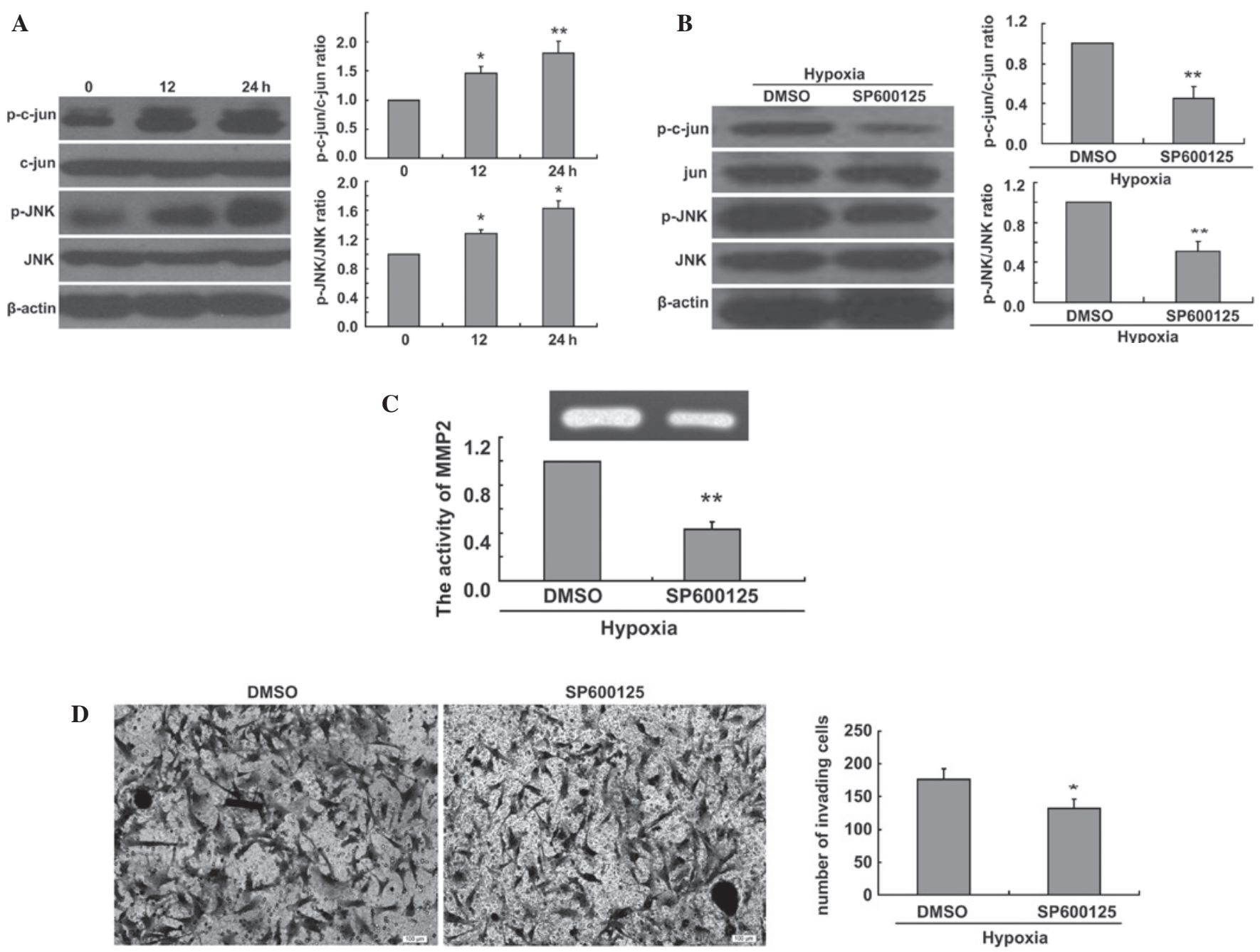

Figure 2. Inhibition of JNK decreases ratio of p-c-jun/c-jun and p-JNK/JNK, MMP2 activity and glioma cell invasion in hypoxic conditions. (A) Western blot analysis shows the time-dependent effect of hypoxia on ratio of p-jun/jun and p-JNK/JNK in U251 cells. The bar graph shows relative ratio of p-jun/jun and p-JNK/JNK in hypoxia-treated cells versus those in control cells ( $\left.{ }^{*} \mathrm{P}<0.05,{ }^{* *} \mathrm{P}<0.01\right)$. (B) Western blot analysis shows ratio of $\mathrm{p}$-jun/jun and $\mathrm{p}-\mathrm{JNK} / \mathrm{JNK}$ in U251 cells treated with $30 \mu \mathrm{mol} / 1 \mathrm{SP} 600125$ in hypoxic conditions for 24h. The bar graph shows relative ratio of p-c-jun/c-jun and p-JNK/JNK in JNK inhibitor-treated cells versus those in control cells $\left({ }^{* *} \mathrm{P}<0.01\right)$. (C) U251 cells treated with $30 \mu \mathrm{mol} / 1 \mathrm{SP} 600125$ were incubated in hypoxic conditions for $24 \mathrm{~h}$ and cell culture medium samples were collected. Gelatin zymography assays show the effect of SP600125 on enzymatic activity of MMP2 under hypoxic conditions. The bar graph shows the relative integrated densities of the bands in treated cells versus those in control cells $\left(^{* *} \mathrm{P}<0.01\right)$. (D) U251 cells treated with $30 \mu \mathrm{mol} / 1$ SP600125 were incubated in a Transwell chamber in hypoxic conditions for $24 \mathrm{~h}$, and the cells were stained with Coomassie Brilliant Blue. The bar graph shows mean number of migrated cells $($ ( $\mathrm{P}<0.05)$.

signaling mechanisms involved in the increased MMP2 activity and tumor cell invasion under hypoxic conditions. However, both P38/Akt and PI3K/Akt were found to modulate the activity of MMP2 in glioma cells (27). Furthermore, it was found that JNK inhibition reduced MMP2 activity in osteosarcoma cells (30). N-terminal phosphorylation of c-Jun by JNK is thought to increase transcription to target gene promoters, including the MMP2 promoter $(28,29)$. In our study, we found that activity of MMP2 was reduced by the inhibition of JNK in glioma cells in hypoxic conditions. This is supported by our finding that JNK inhibition by treatment with SP600125 reduced MMP2 activity and expression of p-c-jun, and decreased cell invasion induced by hypoxia. It suggests the involvement of JNK in the glioma invasion process under hypoxic conditions.

It was found that geranylgeranylation played a predominant role in the regulation of the JNK-MMP2-osteosarcoma cell invasion cascade through the downstream target GTPase RhoA (30). We then sought to identify whether RhoA may play the same role in glioma cell invasion in hypoxic conditions. We found that inhibition of RhoA geranylgeranylation or knockdown of RhoA inhibited the JNK-c-jun signaling pathway and decreased the activity of MMP2 and glioma cell invasion in hypoxic conditions, which indicates that RhoAGTPase plays an important role in glioma cell invasion in hypoxic conditions.

In summary, our data reveal a molecular mechanism by which the inhibition of RhoA geranylgeranylation or knockdown of RhoA results in inhibition of the JNK-c-jun signaling pathway, decreased MMP2 activity and cell invasion in glioma cells in hypoxic conditions. These in vitro findings may contribute to our understanding of the mechanisms that impact glioma cell invasion in hypoxic conditions and provide a novel therapeutic strategy in the treatment of glioma. 
A
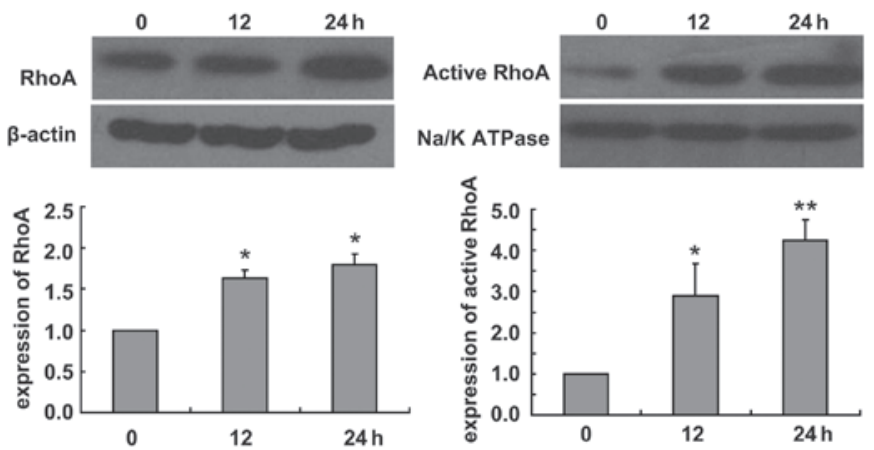

B

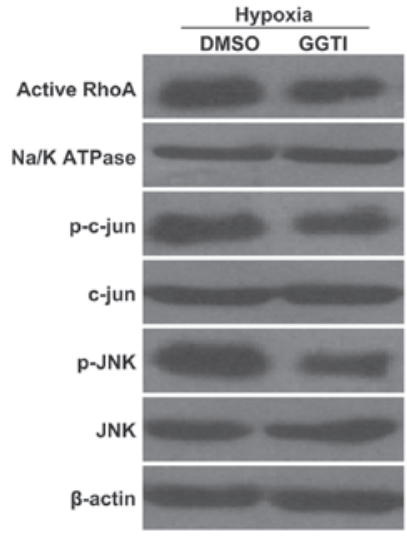

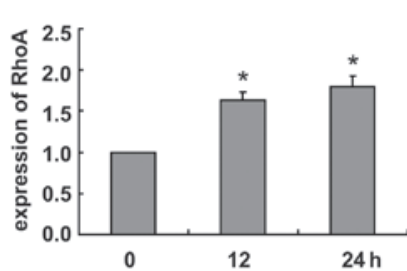

Hypoxia
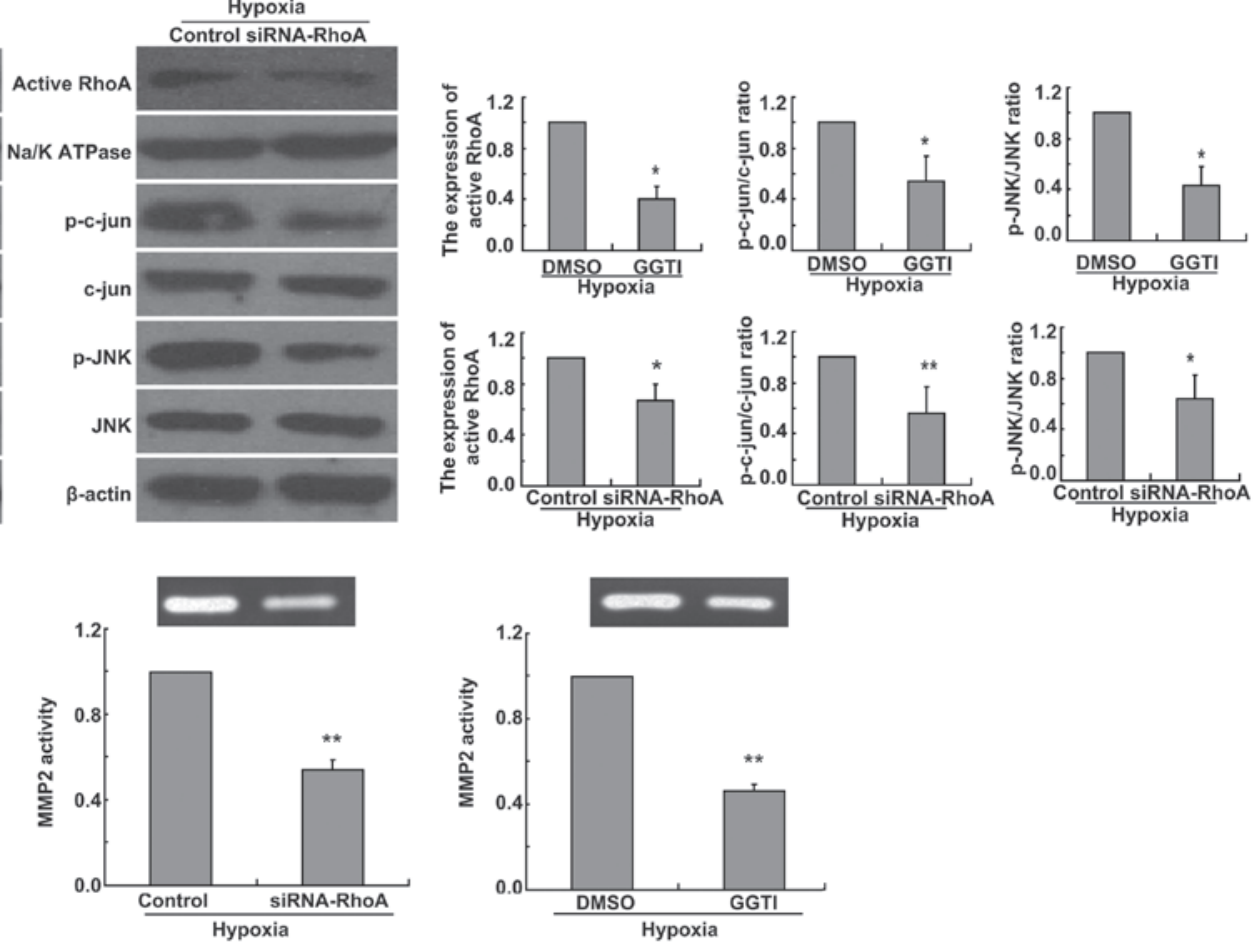

oom

C

$\mathbf{D}$

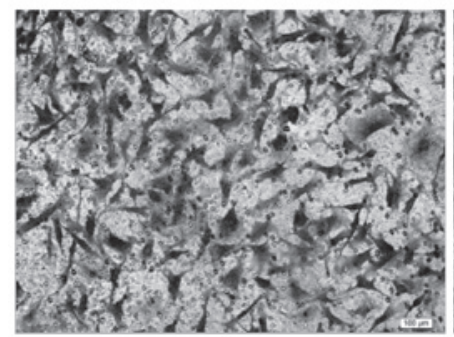

Control

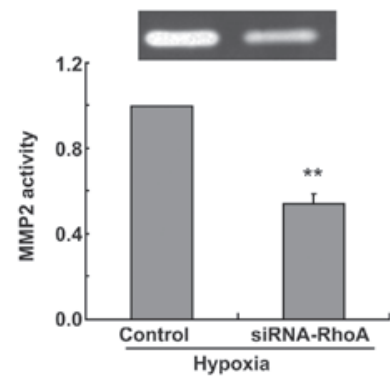

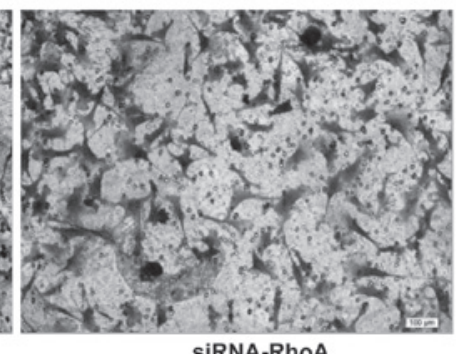

siRNA-RhoA

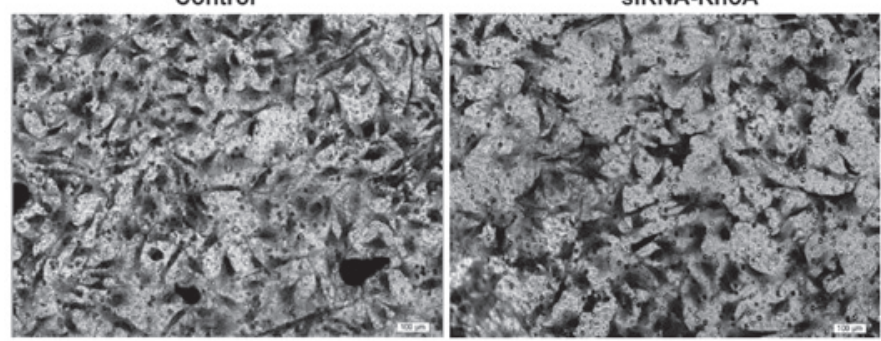

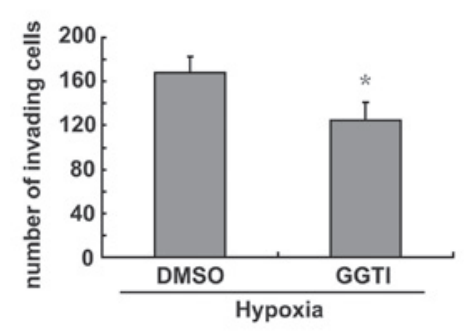

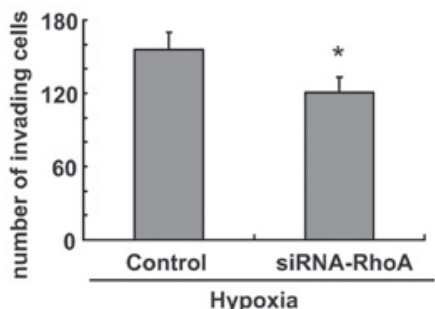

Figure 3. Inactivition or knockdown of RhoA inhibits JNK signaling pathway and decreases MMP2 activity and glioma cell invasion in hypoxic conditions. (A) Western blot analysis shows the time-dependent effect of hypoxia on levels of RhoA and active RhoA in U251 cells. Bar graph shows relative levels of RhoA and active RhoA in hypoxia-treated vs. control cells. (B) Western blot analysis shows expression levels of active RhoA and ratio of p-c-jun/c-jun and p-JNK/ JNK in U251 cells treated with $10 \mu \mathrm{mol} / 1$ GGTI-2147 or transfected with RhoA siRNA in hypoxic conditions for $24 \mathrm{~h}$. Bar graph shows relative active RhoA protein levels, and ratio of p-c-jun/c-jun and p-JNK/JNK vs. those in control cells. (C) U251 cells treated with $10 \mu$ mol/1 GGTI-2147 or transfected with RhoA siRNA were incubated in hypoxic conditions for $24 \mathrm{~h}$ and cell culture medium samples were collected. Gelatin zymography assays showing enzymatic activity of MMP2 secreted by glioma cells treated with $10 \mu \mathrm{mol} / 1$ GGTI-2147 or transfected with RhoA siRNA in hypoxic conditions. Bar graph shows relative integrated densities of bands in treated vs. control cells. (D) U251 cells treated with $10 \mu \mathrm{mol} / 1 \mathrm{GGTI}-2147$ or transfected with RhoA siRNA were incubated in transwell chamber in hypoxic conditions for $24 \mathrm{~h}$ and stained with Coomassie Brilliant Blue. Bar graph shows mean number of migrated cells. ${ }^{*} \mathrm{P}<0.05$; ${ }^{* *} \mathrm{P}<0.01$. 


\section{References}

1. Loeper S, Romeike BF, Heckmann N, Jung V, Henn W, Feiden W, Zang KD and Urbschat S: Frequent mitotic errors in tumor cells of genetically microheterogeneous glioblastomas. Cytogenet Cell Genet 94: 1-8, 2001

2. Wu M, Chen Q, Li D, Li X, Li X, Huang C, Tang Y, Zhou Y, Wang D, Tang K, et al: LRRC4 inhibits human glioblastoma cells proliferation, invasion, and proMMP-2 activation by reducing SDF-1 alpha/CXCR4-mediated ERK1/2 and Akt signaling pathways. J Cell Biochem 103: 245-255, 2008.

3. Louis DN, Ohgaki H, Wiestler OD, Cavenee WK, Burger PC, Jouvet A, Scheithauer BW and Kleihues P: The 2007 WHO classification of tumours of the central nervous system. Acta Neuropathol 114: 97-109, 2007.

4. Maher EA, Furnari FB, Bachoo RM, Rowitch DH, Louis DM, Cavenee WK and DePinho RA: Malignant glioma: genetics and biology of a grave matter. Gene Dev 15: 1311-1333, 2001.

5. Stupp R, Mason WP, van den Bent MJ, Weller M, Fisher B, Taphoorn MJB, et al: Radiotherapy plus concomitant and adjuvant temozolomide for glioblastoma. New Engl J Med 352: 987-996, 2005.

6. Hockel M, Schlenger K, Aral B, et al: Association between tumor hypoxia and malignant progression in advanced cancer of the uterine cervix. Cancer Res 56: 4509-4515, 1996.

7. Woodhouse EC, Chuaqui RF and Liotta LA: General mechanisms of metastasis. Cancer 80: 1529-1537, 1997.

8. Van Noorden CJ: Proteases and protease inhibitors in cancer. Acta Histochem 100: 344-354, 1998.

9. Sternlicht MD and Werb Z: How matrix metalloproteinases regulate cell behavior. Annu Rev Cell Dev Biol 17: 463-516, 2001.

10. Choe G, Park JK, Jouben-Steele L, Kremen TJ, Liau LM, et al: Active matrix metalloproteinase 9 expression is associated with primary glioblastoma subtype. Clin Cancer Res 8: 2894-2901, 2002.

11. Egeblad M and Werb Z: New functions for the matrix metalloproteinases in cancer progression. Nat Rev Cancer 2: 161-174, 2002.

12. Forsyth PA, Wong H, Laing TD, Rewcastle NB, Morris DG, et al: Gelatinase-A (MMP-2), gelatinase-B (MMP-9) and membrane type matrix metalloproteinase-1 (MT1-MMP) are involved in different aspects of the pathophysiology of malignant gliomas. Br J Cancer 79: 1828-1835, 1999.

13. Vogt A, Sun J, Qian Y, Hamilton AD and Sebti SM: The geranylgeranyltransferase-I inhibitor GGTI-298 arrests human tumor cells in G0/G1 and induces p21 (WAF1/CIP1/SDI1) in a p53-independent manner. J Biol Chem 272: 27224-27229, 1997.

14. Laufs U and Liao JK: Post-transcriptional regulation of endothelial nitric oxide synthase mRNA stability by Rho GTPase. J Biol Chem 273: 24266-24271, 1998.

15. Noguchi Y, Nakamura S, Yasuda T, Kitagawa M, Kohn LD, Saito Y and Hirai A: Newly synthesized RhoA, not Ras, is isoprenylated and translocated to membranes coincident with progression of the G1 to S phase of growth-stimulated rat FRTL-5 cells. J Biol Chem 273: 3649-3653, 1998.
16. Wong WW, Dimitroulakos J, Minden MD and Penn LZ: HMG-CoA reductase inhibitors and the malignant cell: the statin family of drugs as triggers of tumor-specific apoptosis. Leukemia 16, 508-519, 2002.

17. Graaf MR, Richel DJ, van Noorden CJ and Guchelaar HJ: Effects of statins and farnesyltransferase inhibitors on the development and progression of cancer. Cancer Treat Rev. 30, 609-641, 2004.

18. Denoyelle C, Vasse M, Korner M, Mishal Z, Ganne F, Vannier JP, Soria $\mathrm{J}$ and Soria C: Cerivastatin, an inhibitor of HMG-CoA reductase, inhibits the signaling pathways involved in the invasiveness and metastatic properties of highly invasive breast cancer cell lines: an in vitro study. Carcinogenesis 22: 1139-1148, 2001.

19. Sawada K, Morishige K, Tahara M, Kawagishi R, Ikebuchi Y, Tasaka K and Murata YL: Alendronate inhibits lysophosphatidic acid-induced migration of human ovarian cancer cells by attenuating the activation of rho. Cancer Res 62: 6015-6020, 2002.

20. Kusama T, Mukai M, Tatsuta M, Nakamura H and Inoue M: Inhibition of transendothelial migration and invasion of human breast cancer cells by preventing geranylgeranylation of Rho. Int J Oncol 29: 217-223, 2006.

21. Sullivan R and Graham CH: Hypoxia-driven selection of the metastatic phenotype. Cancer Metastasis Rev 26: 319-331, 2007.

22. Fujiwara S, Nakagawa K, Harada H, Nagato S, Furukawa K, Teraoka M, Seno T, Oka K, Iwata S and Ohnishi T: Silencing hypoxia-inducible factor-1alpha inhibits cell migration and invasion under hypoxic environment in malignant gliomas. Int $\mathrm{J}$ Oncol 30: 793-802, 2007.

23. Bruland OS, Hoifodt H, Saeter G, Smeland S and Fodstad O: Hematogenous micrometastases in osteosarcoma patients. Clin Cancer Res 11: 4666-4673, 2005.

24. Coussens LM, Fingleton B and Matrisian LM: Matrix metalloproteinase inhibitors and cancer: trials and tribulations. Science 295: 2387-2392, 2002.

25. Egeblad M and Werb Z: New functions for the matrix metalloproteinases in cancer progression. Nat Rev Cancer 2: 161-174, 2002.

26. Forsyth PA, Wong H, Laing TD, Rewcastle NB, Morris DG, et al: Gelatinase-A (MMP-2), gelatinase-B (MMP-9) and membrane type matrix metalloproteinase-1 (MT1-MMP) are involved in different aspects of the pathophysiology of malignant gliomas. Br J Cancer 79: 1828-1835, 1999.

27. Park CM, Park MJ, Kwak HJ, Lee HC, Kim MS, Lee SH, Park IC, $\mathrm{Rhee} \mathrm{CH}$ and Hong SI: Ionizing radiation enhances matrix metalloproteinase-2 secretion and invasion of glioma cells through Src/epidermal growth factor receptor-mediated p38/Akt and phosphatidylinositol 3-kinase/Akt signaling pathways. Cancer Res 66: 8511-8519, 2006.

28. Arias J, Alberts AS, Brindle P, Claret FX, Smeal T, Karin M, Feramisco J and Montminy M: Activation of cAMP and mitogen responsive genes relies on a common nuclear factor. Nature 370: 226-229, 1994.

29. Bannister AJ, Oehler T, Wilhelm D, Angel P and Kouzarides T: Stimulation of c-Jun activity by CBP: c-Jun residues Ser63/73 are required for $\mathrm{CBP}$ induced stimulation in vivo and $\mathrm{CBP}$ binding in vitro. Oncogene 11: 2509-2514, 1995.

30. Fromigué O, Hamidouche Z and Marie PJ: Blockade of the RhoA-JNK-c-Jun-MMP2 cascade by atorvastatin reduces osteosarcoma cell invasion. J Biol Chem 283: 30549-30556, 2008. 